\title{
Prolonged rupture of membranes, pre-eclamptic toxaemia, and respiratory distress syndrome
}

\author{
MALCOLM L. CHISWICK \\ From the Special Care Baby Unit, St. Mary's Hospital, Manchester
}

\begin{abstract}
Chiswick, M. L. (1976). Archives of Disease in Childhood, 51, 674. Prolonged rupture of membranes, pre-eclamptic toxaemia, and respiratory distress syndrome. A retrospective analysis was made of the incidence and severity of the idiopathic respiratory distress syndrome (RDS) in babies of less than 35 weeks' gestation born at this hospital from January 1967-December 1974. There was a lower incidence of RDS in babies born after pregnancies complicated only by prolonged rupture of membranes (PRM) (19\%) and in babies born vaginally after pregnancies complicated only by pre-eclamptic toxaemia (PET) (18\%) compared with the incidence of RDS after uncomplicated pregnancies (35\%). Babies born vaginally who developed RDS after pregnancies complicated by PRM or PET had less severe disease compared with those who developed RDS after uncomplicated pregnancies. Mortality in babies who developed severe RDS was not influenced by the occurrence of PRM or PET. The biological implication of the study is that certain complications of pregnancy may accelerate pulmonary surfactant production in preterm babies.
\end{abstract}

A sharp increase in the concentration of amniotic fluid dipalmitoyl lecithin occurs in normal pregnancies at 35-36 weeks of gestation indicating functional maturation of the fetal pulmonary surfactant system (Gluck et al., 1972). Endogenous glucocorticoids play a role in the development of pulmonary surfactant in animals (Blackburn, Travers, and Potter, 1972; Chiswick et al., 1973) and probably in humans (Naeye, Harcke, and Blanc, 1971). Development of pulmonary surfactant in many animal species is accelerated by administration of glucocorticoids to the fetus (Liggins, 1969; Kotas and Avery, 1971), and administration of glucocorticoids to mothers may possibly be associated with the precocious development of pulmonary surfactant in human fetuses (Liggins and Howie, 1972).

Against this background we examine the hypothesis that certain complications of pregnancy which are stressful to the fetus are associated with precocious development of pulmonary surfactant, and thereby protect the preterm baby against the development of the idiopathic respiratory distress syndrome (RDS). Several investigators have sug-

Received 8 January 1976. gested that prolonged rupture of membranes (PRM) might have a beneficial effect in protecting preterm babies from developing RDS (Yoon and Harper, 1973; Bauer, Stern, and Colle, 1974; Richardson et al., 1974). However, an extensive study by Jones et al. (1975) failed to show an association between PRM and RDS, and the issue remains controversial.

\section{Subjects and methods}

Neonatal case histories and corresponding maternal histories of liveborn babies of less than 35 weeks' gestation born at St. Mary's Hospital, Manchester, from January 1967 to December 1974 were examined. Babies whose birthweights were $<700 \mathrm{~g}$ were not studied. Gestational age was calculated from the date of the mother's last menstrual period. When a discrepancy of 4 weeks or more occurred between gestational age as calculated from the last menstrual period and that determined by clinical examination (Robinson, 1966), the baby was excluded from the study.

The incidence and severity of RDS was compared in babies of less than 35 weeks' gestation who were born after pregnancies complicated only by PRM (group I), complicated only by pre-eclamptic toxaemia (PET) (group II) and after apparently uncomplicated pregnancies (group III). Pregnancies or births complicated by factors which might influence the occurrence of RDS, 
such as antepartum haemorrhage, $\mathrm{Rh}$-haemolytic disease, diabetes mellitus, multiple pregnancy, and birth asphyxia (failure to establish spontaneous respiration by one minute after birth), were excluded. All babies in groups I and III were born vaginally, whereas a proportion of babies in group II were delivered by caesarean section because of severe PET, and were included in the study so that the influence of PET on the occurrence of RDS after vaginal or caesarean section delivery could be separately assessed.

Definitions. PRM Documented evidence of drainage of liquor amnii occurring 24 hours or more before delivery. PET Presence of at least two of the following signs on two or more occasions after the 24th week of pregnancy: blood pressure $>140 / 90 \mathrm{mmHg}$, oedema, proteinuria. $R D S$ Presence of two or more of the following signs at the age of 4 hours: respiratory rate $>60 / \mathrm{min}$, thoracic cage recession on inspiration, expiratory grunt or whine. Diagnosis was supported by the presence of fine mottling on a chest $x$-ray taken during the course of the disease. Mild $R D S$ Survivors with signs of RDS of $<48$ hours' duration. Severe RDS Survivors with signs of RDS of 48 hours' duration or longer plus deaths associated with RDS. Deaths associated with RDS Deaths occurring within 96 hours of birth associated with signs of RDS and post-mortem findings of pulmonary hyaline membranes.

The $\chi^{2}$ test with Yates's correction was used for statistical analysis of data.

\section{Results}

There were 32285 live births during the period of study and $807(2 \cdot 5 \%)$ occurred before 35 completed weeks of gestation associated with birthweights greater than $700 \mathrm{~g}$. Complications of pregnancy other than PRM and PET occurred in 323 out of the 807 births, leaving a total of 477 babies who were the subjects of the study.

There was no significant difference in the gestational age distribution or male:female sex ratio between the three groups (Table I). Birthweights of $15 \%$ of babies in group I, $19 \%$ in group II, and $13 \%$ in group III were $<10$ th centile for gestational age (birthweight centile charts of Thomson, Billewicz, and Hytten, 1968; Babson, Behrman, and Lessel, 1970). The difference in the incidence of light-for-dates babies in the three groups was not significant.

PRM. The incidence of RDS was significantly lower in babies born after pregnancies complicated by PRM (19\%) compared with the incidence in babies of uncomplicated pregnancies (35\%; $\mathrm{P}<0.005$; Table II). Within each gestational age

\section{TABLE II}

Incidence of RDS in babies of $<35$ weeks' gestation born after pregnancies complicated by PRM, PET, or after uncomplicated pregnancies

\begin{tabular}{l|c|c|c}
\hline Complication of pregnancy & Total no. & RDS & $\%$ \\
\hline PRM (group I) & 106 & 20 & $19 \star$ \\
PET (group II) & 29 & 9 & 31 \\
CS & 60 & 11 & $18 \dagger$ \\
VD & 89 & 20 & $22 \cdot 5 \ddagger$ \\
Both & 282 & 99 & 35 \\
Uncomplicated (group III) & & & \\
\hline
\end{tabular}

${ }^{\star} \chi^{2}=8.8, P<0.005$

$\left.+x^{2}=5.63, P<0.025\right\}$ compared with group III.

$\mp \chi^{2}=4.39, P<0.05$

range ( $<29,29-31,32-34$ weeks) the incidence of RDS was lower in babies born after PRM than in those born after uncomplicated pregnancies, though the differences were not significant (Table III). The incidence of RDS in babies born more than 48 hours after membrane rupture $(9 \cdot 5 \%)$ was lower compared with the incidence of RDS in babies born 24-48 hours after membrane rupture $(21 \%)$, but this finding was not significant (see

\section{TABLE I}

Gestational age distribution and male:female sex ratio of babies born after pregnancies complicated by prolonged rupture of membranes (PRM), pre-eclamptic toxaemia (PET), or after uncomplicated pregnancies

\begin{tabular}{|c|c|c|c|c|c|c|c|c|c|}
\hline \multirow{3}{*}{ Complications of pregnancy } & \multicolumn{9}{|c|}{ Gestational age (w) } \\
\hline & \multicolumn{3}{|c|}{$<29$} & \multicolumn{3}{|c|}{ 29-31 } & \multicolumn{3}{|c|}{$32-34$} \\
\hline & No. & $\%$ & $\mathbf{M}: \mathbf{F}$ & No. & $\%$ & $\mathbf{M}: \mathbf{F}$ & No. & $\%$ & $\mathbf{M}: \mathbf{F}$ \\
\hline $\begin{array}{l}\text { PRM (group I) } \\
\text { PET (group II) } \\
\text { CS } \\
\text { VD } \\
\text { Both } \\
\text { Uncomplicated (group III) }\end{array}$ & $\begin{array}{r}21 \\
7 \\
17 \\
24 \\
51\end{array}$ & $\begin{array}{l}20 \\
24 \\
28 \\
27 \\
18\end{array}$ & $\begin{array}{l}1 \cdot 33: 1 \\
1 \cdot 33: 1 \\
1 \cdot 42: 1 \\
1 \cdot 4: 1 \\
1 \cdot 55: 1\end{array}$ & $\begin{array}{r}21 \\
9 \\
15 \\
24 \\
65\end{array}$ & $\begin{array}{l}20 \\
31 \\
25 \\
27 \\
23\end{array}$ & $\begin{array}{l}1 \cdot 1: 1 \\
1 \cdot 25: 1 \\
1 \cdot 14: 1 \\
1 \cdot 18: 1 \\
1 \cdot 16: 1\end{array}$ & $\begin{array}{r}64 \\
13 \\
28 \\
41 \\
166\end{array}$ & $\begin{array}{l}60 \\
45 \\
47 \\
46 \\
59\end{array}$ & $\begin{array}{l}1 \cdot 2: 1 \\
1 \cdot 16: 1 \\
1 \cdot 33: 1 \\
1 \cdot 27: 1 \\
1 \cdot 21: 1\end{array}$ \\
\hline
\end{tabular}

CS, caesarean section; VD, vaginal delivery. 
TABLE III

Incidence of RDS in preterm babies of different gestational ages, born after pregnancies complicated by PRM, $P E T$, or after uncomplicated pregnancies

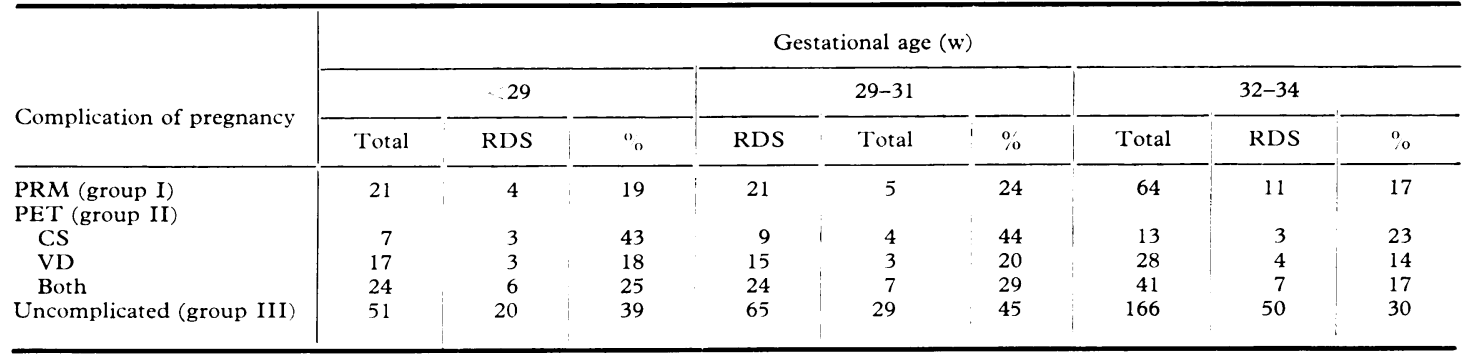

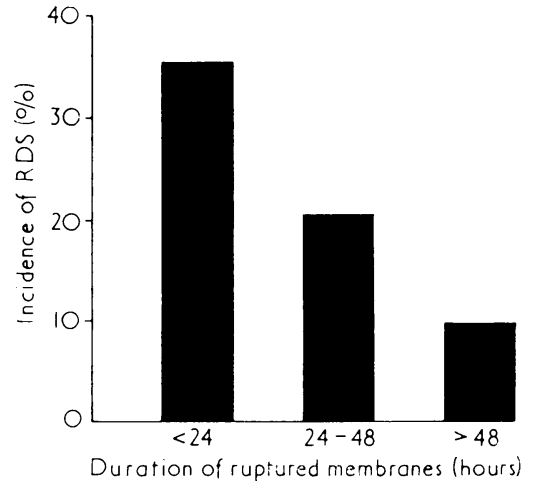

Fig.-Influence of the duration of ruptured membranes on the incidence of idiopathic respiratory distress syndrome

$(R D S)$ in babies of less than 35 weeks' gestation.

Fig.). The incidence of severe disease in babies with RDS after PRM $\left(35^{\circ}{ }_{0}\right)$ was lower compared with the incidence of severe disease in babies with RDS who were born after uncomplicated pregnancies $\left(66^{\circ}{ }_{0}^{\prime}\right)$ (Table IV). There was no difference

\section{TABLE IV}

Incidence of severe RDS in babies of $<35$ weeks' gestation born after pregnancies complicated by PRM, PET, or after uncomplicated pregnancies

\begin{tabular}{|c|c|c|c|}
\hline \multirow{2}{*}{ Complications of pregnancy } & \multicolumn{2}{|c|}{ RDS } & \multirow{2}{*}{${ }^{\circ}$} \\
\hline & Total & Severe & \\
\hline $\begin{array}{l}\text { PRM (group I) } \\
\text { PET (group II) }\end{array}$ & 20 & 7 & $35^{\star}$ \\
\hline CS & 9 & 8 & 89 \\
\hline VD & 11 & 2 & $18+$ \\
\hline Both & 20 & 10 & 50 \\
\hline Uncomplicated (group III) & 99 & 65 & 66 \\
\hline
\end{tabular}

$\left.\star_{\gamma^{2}}^{2}=5 \cdot 32, \mathrm{P}<0.025\right\}$ Compared with group III.

$\dagger \varkappa^{2}=7 \cdot 48, \mathrm{P}<0 \cdot 01$
$+\%^{2}=7 \cdot 27, \mathrm{P}<0 \cdot 01$, compared with group II, CS between the mortality in babies with severe RDS who were born after PRM and those with severe RDS born after uncomplicated pregnancies (Table $\mathrm{V})$.

\section{TABLE V}

Incidence of mortality in babies with severe RDS born at $<35$ weeks' gestation after pregnancies complicated by PRM, PET, or after uncomplicated pregnancies

\begin{tabular}{l|c|c|c}
\hline \multirow{2}{*}{ Complications of pregnancy } & \multicolumn{2}{|c|}{ Severe RDS } & \\
\cline { 2 - 3 } & Total & Deaths & \\
\hline PRM (group I) & 7 & 4 & 57 \\
PET (group II) & & & \\
CS & 8 & 5 & 63 \\
VD & 2 & 1 & 50 \\
Both & 65 & 6 & 60 \\
Uncomplicated (group III) & & 37 & 57 \\
& & & \\
\hline
\end{tabular}

PET. The incidence of RDS was lower in babies born after pregnancies complicated by PET $(22.5 \%)$ compared with the incidence in babies of uncomplicated pregnancies $(35 \% ; \quad \mathrm{P}<0.05$; Table II). Delivery by caesarean section for severe PET was performed in 29 out of the 89 cases in group II. When the incidence of RDS in babies of group II who were born by the vaginal route $\left(18^{\circ}\right)$ was compared with the incidence of RDS after uncomplicated pregnancies $(35 \%)$ the apparent 'protective' influence of PET became even more significant $(P<0 \cdot 025)$. In contrast, there was a similar incidence of RDS in babies of group II who were born by caesarean section and babies born after uncomplicated pregnancies (Table II). Within each gestational age range the incidence of RDS in babies born by the vaginal route in group II was lower compared with the incidence of RDS after uncomplicated pregnancies, though this finding was not significant (Table III). 
The incidence of severe disease in babies with RDS in group II did not differ significantly from the incidence of severe disease in babies with RDS born after uncomplicated pregnancies. However, babies in group II who developed RDS after vaginal delivery had a lower incidence of severe disease $(18 \%)$ compared with babies in group II who developed RDS after caesarean section delivery $89 \% ; \mathrm{P}<0.01)$ and compared with babies who developed RDS after uncomplicated pregnancies $(66 \% ; P<0.01$; Table IV). There was no significant difference between the mortality in babies in group II with severe RDS, and the mortality in babies with severe RDS born after uncomplicated pregnancies (Table V).

\section{Discussion}

A protective effect of PRM against the development of RDS has been suggested by other workers (Yoon and Harper, 1973; Bauer et al., 1974; Richardson et al., 1974). However, Jones et al. (1975), failed to show an association between PRM and the occurrence of RDS, and suggested that in previous studies babies born after PRM had been inadequately matched for gestational age with controls. In the present study all subjects were of less than 35 weeks' gestation and were divided into gestational age ranges of 3 weeks. Distribution of gestational age between babies born after PRM and those born after uncomplicated pregnancies was almost identical. Within each gestational age range the incidence of RDS after pregnancies complicated by PRM was approximately one-half that after uncomplicated pregnancies. Undoubtedly, the low incidence of RDS in babies of less than 35 weeks' gestation born after PRM compared with those of less than 35 weeks' gestation born after uncomplicated pregnancies has biological as well as statistical significance. However, when PRM occurred it was the only complication of pregnancy apart from preterm delivery, and there were no apparent complications of pregnancy apart from preterm delivery in the 'control' group. This fact probably underlies the discrepancy between the present findings and those of Jones et al. (1975) whose data refer to the influence of PRM on the incidence of RDS in babies born after pregnancies complicated by such factors as diabetes mellitus, antepartum haemorrhage, birth asphyxia, etc. A protective effect of PRM may well be nullified in the presence of other complications of pregnancy which adversely influence the occurrence of RDS.

The beneficial effect of PRM was not an 'all or none' phenomenon and when RDS occurred in spite of PRM the disease was more likely to be mild compared with severe disease after uncomplicated pregnancies. A retrospective assessment of the severity of RDS is difficult. Assessment by chest radiology would have been heavily influenced by the timing and frequency of the investigation. Severity of RDS could be measured by the maximum inspired oxygen concentration $\left(\mathrm{F}_{1} \mathrm{O}_{2}\right)$ to which the baby was exposed during the course of the illness. This method would be satisfactory if $\mathrm{F}_{\mathrm{I}} \mathrm{O}_{2}$ were always based on the results of arterial blood gas analysis. Clinical practice with respect to arterial blood sampling was not constant during the period of investigation, with a trend towards more frequent usage in babies born during the latter part of the study. Justification for assessing the severity of RDS in terms of the duration of clinical signs was that throughout the period of study nursing records had been made on each patient with RDS in which respiratory rate, grunting, and thoracic cage recession had been carefully documented at 4-hourly intervals. A year-by-year analysis of the incidence and severity of RDS in our subjects showed no significant secular trend.

It is possible that PRM was associated with precocious fetal lung development, thereby explaining the relatively low incidence of RDS in babies born after PRM. Richardson et al. (1974) measured amniotic fluid lecithin/sphingomyelin ratios in pregnancies complicated by PRM and observed that this event had an accelerating effect on fetal lung development. Circumstantial evidence suggests that in the present study the beneficial effect of PRM might have been associated with precocious pulmonary surfactant development induced by fetal or maternally transmitted glucocorticoids. Bauer et al. (1974) showed that there was a positive correlation between the plasma cortisol concentration in infants soon after delivery and the duration of ruptured membranes before delivery.

Placentae from 1000 consecutive live births at St. Mary's Hospital, Manchester were examined by Fox and Langley (1971). Fortuitously, there were data from a group of pregnancies of less than 35 weeks' gestation complicated by PRM. The incidence of placental leucocytic infiltration was $80 \%$. Blanc $(1959,1961)$ showed that placental leucocytic infiltration was invariably associated with the presence of organisms in the amniotic fluid, and Kelsall, Barter, and Manessis (1967) showed a positive correlation between fetal bacteraemia and placental leucocytic infiltration. Several lines of evidence suggest that fetal infection may augment fetal glucocorticoid secretion. Naeye et al. (1971) observed in a study of neonatal necropsy material 
that infants infected before birth had larger adrenal glands and were less likely to have hyaline membrane disease compared with noninfected infants. Histological changes in the adrenal glands consistent with a severe 'stress reaction' were reported by deSa (1974) in 4 preterm stillborn infants whose placentae had histological features of chorioamnionitis. The infecting agent was known in 3 cases (Candida albicans, $\beta$-haemolytic streptococcus, Haemophilus influenzae). Intrauterine infection of fetal lambs was associated with enhanced fetal adrenocortical activity as evidenced by histology of the adrenal glands and plasma cortisol levels compared with noninfected fetal lambs of an equivalent gestational age (Osburn, Drost, and Stabenfeldt, 1972). The observation of Kotas (1973) that intrauterine inoculation of rabbit fetuses with Staphylococcus aureus was associated with accelerated development of pulmonary surfactant supports the hypothesis that fetoplacental infection protects the newborn baby against RDS.

A protective effect of PET against RDS was shown in those babies who were born by the vaginal route. One direct observation which suggests that pregnancy complicated by PET might be associated with precocious surfactant development in the fetus was the finding by Gluck and Kulovich (1973) that pregnancies complicated by 'chronic toxaemia' were associated with the accelerated appearance of 'mature' lecithin/sphingomyelin ratios in amniotic fluid. The possible role of fetal or maternal glucocorticoids in precocious surfactant development in such pregnancies is unclear. There appear to be no relevant data concerning plasma cortisol levels in preterm babies born after pregnancies complicated by PET. Kopelman and Levitz (1970) observed that the mean maternal plasma cortisol concentration is normal pregnancy and pregnancy complicated by PET was not significantly different. Mukherjee and Swyer (1972) showed that pregnancies complicated by PET were associated with raised maternal plasma ACTH levels and reduced maternal cortisol levels compared with uncomplicated pregnancies, the authors suggesting that the maternal adrenal gland in PET may be relatively unresponsive to ACTH stimulation. Transplacental transfer of ACTH cannot be ruled out under these conditions.

Several reports, including one by Hendricks and Brenner (1971), highlight the association of PET with poor socioeconomic status. In the present study the inclusion of a large number of mothers of low socioeconomic status in association with PET might have provided associated maternal factors such as poor nutrition and infection which per se could have produced a 'stressful' fetal environment and enhanced fetal adrenal glucocorticoid secretion. Naeye (1974) showed that babies of poorly nourished mothers had more mature lungs based on morphological and biochemical characteristics compared with babies of an equivalent gestational age who were born to well-nourished mothers. Davies (1966) observed that the incidence of RDS was lower in infants whose birthweight was more than one standard deviation below the mean weight for a given gestational age, compared with heavier infants. In the present study it is unlikely that fetal growth retardation per se influenced the occurrence of RDS because the incidence of light-for-dates babies in the three groups was not significantly different.

Certain other hormonal factors which may operate in pregnancies complicated by PET have to be considered. Genazzani, Fioretti, and Lemarchand-Beraud (1971) observed raised maternal levels of plasma thyroid stimulating hormone compared with uncomplicated pregnancies, and the hormone may be of placental origin (Hennen, 1965; Hershman and Starnes, 1969). Thyroxine stimulates pulmonary surfactant development in animals (Redding, Douglas and Stein, 1972; Wu et al., 1973). Placental transfer of thyroid stimulating hormone and stimulation of the fetal thyroid gland cannot be excluded in pregnancies complicated by PET. Sprague et al. (1973) observed that the levels of human chorionic somatotrophin in fetal blood were markedly raised in pregnancies complicated by PET compared with uncomplicated pregnancies. The hormone has immunological cross-reaction with pituitary growth hormone and also has a growth promoting action. There is no information on the influence of this hormone on fetal lung development and this seems to be a relevant investigation particularly as the presence of the hormone is confined to fetal life.

The protective influence of PET against the occurrence of RDS was nullified when delivery was by caesarean section. It is well recognized that delivery by caesarean section has an adverse influence on the occurrence of RDS, though it is unclear whether it is the abnormal delivery itself or the indication for caesarean section which underlies the association. Delivery by caesarean section before 35 weeks' gestation only occurred when PET was uncontrollable or fulminating. It may be argued that the protective influence of PET was nullified because of a possible difference between the effects of mild and severe PET on pulmonary surfactant development. It is unlikely that the presence of severe fetal asphyxia influenced the 
occurrence of RDS as all babies breathed normally by one minute after birth.

The purpose of this study was to explore the biological implications of the influence of PRM and PET on the occurrence of RDS in preterm babies. A practical implication which emerges concerns the design of trials to assess the efficacy of maternally administered glucocorticoids in the prevention of RDS in preterm babies. It has been shown that certain common complications of pregnancy may in their own right protect the baby against the development of RDS.

I thank Professor J. A. Davis for encouragement, and Mrs. M. Willder and staff of the Medical Records Department for their co-operation.

\section{REFBRENCES}

Babson, S. G., Behrman, R. E., and Lessel, R. (1970). Fetal growth. Liveborn birthweights for gestational age of white middle class infants. Pediatrics, 45, 937.

Bauer, C. R., Stern, L., and Colle, E. (1974). Prolonged rupture of membranes associated with a decreased incidence of respiratory distress syndrome. Pediatrics, 53, 7.

Blackburn, W. R., Travers, H., and Potter, D. M. (1972). The role of the pituitary-adrenal-thyroid axes in lung differentiation. I. Studies of the cytology and physical properties of anencephalic fetal rat lung. Laboratory Investigation, 26, 306.

Blanc, W. A. (1959). Amniotic infection syndrome. Clinical Obstetrics and Gynecology, 2, 705.

Blanc, W. A. (1961). Pathways of fetal and neonatal infection. Viral placentitis, bacterial and fungal chorioamnionitis. Fournal of Pediatrics, 59, 473.

Chiswick, M. L., Ahmed, A., Jack, P. M. B., and Milner, R. D. G. (1973). Control of fetal lung development in the rabbit. Archives of Disease in Childhood, 48, 709.

Davies, P. A. (1966). Aetiological factors in the respiratory distress syndrome of the newborn. M.D. thesis, University of Glasgow.

deSa, D. J. (1974). Adrenal changes in chorioamnionitis. Archives of Disease in Childhood, 49, 149.

Fox, H., and Langley, F. A. (1971). Leukocytic infiltration of the placenta and umbilical cord. A clinico-pathologic study. Obstetrics and Gynecology, 37, 451.

Genazzani, A. R., Fioretti, P., and Lemarchand-Beraud, Th. (1971). Plasma thyrotrophin levels during pregnancy. Fournal of Obstetrics and Gynaecology of the British Commonwealth, 78, 117.

Gluck, L., and Kulovich, M. V. (1973). Lecithin/sphingomyelin ratios in amniotic fluid in normal and abnormal pregnancy. American Fournal of Obstetrics and Gynecology, 115, 539.

Gluck, L., Kulovich, M. V., Eidelman, A. I., Cordero, L., and Khazin, A. F. (1972). Biochemical development of surface activity in mammalian lung. IV. Pulmonary lecithin synthesis in the human fetus and newborn and etiology of the respiratory distress syndrome. Pediatric Research, 6, 81 .

Hendricks, C. H., and Brenner, W. E. (1971). Toxemia of pregnancy: relationship between fetal weight, fetal survival and the maternal state. American fournal of Obstetrics and Gynecology, $109,225$.
Hennen, G. (1965). Detection and study of a human-chorionicthyroid stimulating factor. Archives Internationales de Physiologie et de Biochemie, 73, 689.

Hershman, J. M., and Starnes, W. R. (1969). Extraction and characterization of a thyrotropic material from the human placenta. Fournal of Clinical Investigation, 48, 923.

Jones, M. D., Jr., Burd, L. I., Bowes, W. A., Jr., Battaglia, F. C., and Lubchenco, L. O. (1975). Failure of association of premature rupture of membranes with respiratory-distress syndrome. New England fournal of Medicine, 292, 1253.

Kelsall, G. R. H., Barter, R. A., and Manessis, C. (1967). Prospective bacteriological studies in inflammation of the placenta, cord and membranes. Fournal of Obstetrics and Gynaecology of the British Commonwealth, 74, 401.

Kopelman, J. J., and Levitz, M. (1970). Plasma cortisol levels and cortisol binding in normal and pre-eclamptic pregnancies. American fournal of Obstetrics and Gynecology, 108, 925.

Kotas, R. V. (1973). Accelerated pulmonary surfactant after intrauterine infection in the fetal rabbit. Pediatrics, 51, 655.

Kotas, R. V., and Avery, M. E. (1971). Accelerated appearance of pulmonary surfactant in the fetal rabbit. Fournal of Applied Physiology, 30, 358.

Liggins, G. C. (1969). Premature delivery of foetal lambs infused with glucocorticoids. Fournal of Endocrinology, 45, 515.

Liggins, G. C., and Howie, R. N. (1972). A controlled trial of antepartum glucocorticoid treatment for prevention of the respiratory distress syndrome in premature infants. Pediatrics, $50,515$.

Mukheriee, K., and Swyer, G. I. M. (1972). Plasma cortisol and adrenocorticotrophic hormone in normal men and non-pregnant women, normal pregnant women and women with pre-eclampsia. fournal of Obstetrics and Gynaecology of the British Commonwealth, 79, 504.

Naeye, R. L. (1974). Nutrition, sex and fetal lung maturation. American Fournal of Pathology, 74, 93a.

Naeye, R. L., Harcke, H. T., Jr., and Blanc, W. A. (1971). Adrenal gland structure and the development of hyaline membrane disease. Pediatrics, 47, 650.

Osburn, B. I., Drost, M., and Stabenfeldt, G. H. (1972). Response of fetal adrenal cortex to congenital infections. American Fournal of Obstetrics and Gynecology, 114, 622.

Redding, R. A., Douglas, W. H. J., and Stein, M. (1972). Thyroid hormone influence upon lung surfactant metabolism. Science, 175, 994.

Richardson, C. J., Pomerance, J. J., Cunningham, M. D., and Gluck, L. (1974). Acceleration of fetal lung maturation following prolonged rupture of the membranes. American fournal of Obstetrics and Gynecology, 118, 115.

Robinson, R. J. (1966). Assessment of gestational age by neurological examination. Archives of Disease in Childhood, 41, 437.

Sprague, A. D., Duhring, J. L., Moser, R. J., and Hollingsworth, D. (1973). Maternal and fetal levels of HCS in pre-eclampsia. Obstetrics and Gynecology, 41, 770.

Thomson, A. M., Billewicz, W. Z., and Hytten, F. E. (1968). The assessment of fetal growth. Fournal of Obstetrics and Gynaecology of the British Commonwealth, 75, 903.

Wu, B., Kikkawa, Y., Orzalesi, M. M., Motoyama, E. K., Kaibara, M., Zigas, C. J., and Cook, C. D. (1973). The effect of thyroxine on the maturation of fetal rabbit lungs. Biology of the Neonate, 22, 161.

Yoon, J. J., and Harper, R. G. (1973). Observations on the relationship between duration of rupture of the membranes and the development of idiopathic respiratory distress syndrome. Pediatrics, 52, 161.

Correspondence to Dr. M. L. Chiswick, Special Care Baby Unit, St. Mary's Hospital, Hathersage Road, Manchester M13 0JH. 